\title{
SELEÇÃO DE CARAMBOLEIRAS PELAS CARACTERÍSTICAS BIOMÉTRICAS E FÍSICO-QUÍMICAS DOS FRUTOS
}

\author{
Paulo Sérgio Rodrigues de Araújo ${ }^{1 *}$; Keigo Minami² \\ ${ }^{1}$ UNIVALE/CENAG - C.P. 295 - CEP: 35024-820 - Governador Valadares, MG. \\ ${ }^{2}$ Depto. de Produção Vegetal - USP/ESALQ - C.P. 9 - CEP: 13418-900 - Piracicaba, SP. \\ *Autor correspondente <psrarauj@yahoo.com>
}

\begin{abstract}
RESUMO: Caracterizaram-se caramboleiras relacionando as características biométricas e físico-químicas dos frutos. Foram utilizadas 15 caramboleiras de pomar comercial, em Mirandópolis-SP. Procederam-se seis coletas de 50 frutos por planta, no período entre 1997 e 1999, para avaliações biométricas de comprimento, diâmetro, massa, número de gomos e sementes. Nas referidas coletas para avaliação dos parâmetros físico-químicos, utilizaram-se três frutos por planta, sendo analisados: sólidos solúveis totais (SST), acidez total titulável (ATT), "ratio", firmeza de polpa, pH e coloração externa. Duas plantas foram superiores às demais em relação ao comprimento e massa dos frutos, apresentando elevados teores de SST e "ratio", entretanto, baixa ATT, características interessantes para o consumo fresco. Contudo, foi limitante o grande número de sementes de uma planta em relação à outra. Como opção para porta-enxerto, devido ao elevado número de sementes nos frutos, destacaram-se três plantas. Com potencial para processamento foi selecionada uma planta, decorrente da elevada ATT, baixo número de sementes e tamanho do fruto entre médio e grande.
\end{abstract}

Palavras-chave: Averrhoa carambola

\section{SELECTION OF STAR-FRUIT TREES THROUGH BIOMETRICAL AND PHYSICO-CHEMICAL CHARACTERISTICS}

\begin{abstract}
This research evaluated biometrical and physico-chemical characteristics of star-fruit selections. The fruits were collected from 15 star-fruit trees in a commercial orchard of Mirandópolis, SP, Brazil. Six harvest collections of 50 fruits per plant were made between 1997 and 1999. Biometric evaluations included length, diameter, mass, corners and seed numbers. The evaluation of the physico-chemical parameters consisted of three fruits per plant, analyzing total titatrable acidity (TTA), total soluble solids (TTS), ratio, firmness, $\mathrm{pH}$ and skin color. Two plants produced the largest fruits with high TTS content, low number of seeds, although differing in number of seeds. These plants are interesting for grafting in a new scion of clones since the quality of the fruits for fresh consumption was very good. As an option for rootstock, three plants were selected, due to the great number of seeds and high TTA content. Another plant was selected for the industry, due to good fruit size, high TTA content and low number of seeds.
\end{abstract}

Key words: Averrhoa carambola

\section{INTRODUÇÃO}

Decorrente da necessidade da conservação e exploração dos recursos de valor econômico atual e potencial, com um incremento contínuo da busca racional qualitativa e uso eficaz, deveria haver um esforço no sentido de minorar a erosão de fruteiras nativas e exóticas com características tropicais (Ferreira \& Donadio, 1988; Ferreira et al., 1987).

Saúco (1994) referiu-se à caramboleira (Averrhoa carambola L.) como uma das fruteiras com grande potencial, devido à capacidade de rápido desenvolvimento, alta produtividade, seleção de novos tipos doces, possibilidade de cultivo em sistemas baixos (latada, casa de vegetação), fruto com aparência e sabor únicos e a possibilidade em contornar fatores limitantes de cultivo.

A escassez de trabalhos sobre a caramboleira no Brasil, a crescente demanda de informações, o apelo mercadológico quanto ao formato e sabor exóticos, as possibilidades quanto à utilização do fruto, a adaptabilidade da planta às condições edafoclimáticas brasileira, a precocidade, a quantidade, regularidade e vida útil de produção, são parâmetros que induzem a viabilidade de cultivo na maioria do território nacional, exceto nas regiões submetidas a geadas e baixas temperaturas durante longo período.

No Brasil, há pelo menos dez anos, a caramboleira não era considerada como uma fruteira comercial (Narain et al., 1988; Donadio, 1989). Encontrava-se em terceiro lugar, com produção anual em torno de $3.000 \mathrm{t}$, provenientes na sua maioria de pomares domésticos (Donadio, 1989). Ressalta-se a baixa qualidade das plantas e a desuniformidade de produção, pela falta de material vegetal selecionado e da propagação deste ser preponderantemente através de sementes. O principal consumidor é o estado de São Paulo, destacando-se as regiões produtoras de Campinas e Araçatuba, sendo comercializado no CEAGESP-SP no ano de 1999 até o 
mês de setembro, 122.345 caixas $(15,0 \mathrm{Kg})$ e 29.504 caixas $(6,0 \mathrm{Kg})$. A comercialização apresenta sazonalidade, com pico de oferta nos meses de janeiro, fevereiro e março, alcançando maiores preços nos meses de novembro e dezembro(Araújo et al., 2000).

A caramboleira (Averrhoa carambola L.), foi introduzida no Brasil, juntamente com o limão caiano (Averrhoa bilimbi L.) e outras plantas de origem asiática, com a chegada em 01 de maio de 1811 do agrônomo francês Paul Germain, que as trouxe de cultivos em Cayenna para o extinto jardim da Aclimação em Olinda, em Pernambuco, de onde se espalhou para todo o litoral do país (Granato, 1919).

As carambolas são classificadas em dois grandes grupos, o tipo ácido que deve ser consumido após um processo de transformação e o doce, oriundo de seleção recente, que se destina ao consumo fresco, recomendando-se não processar, já que perdem sua identidade após a cocção. Há uma publicação na Flórida que descreve 45 receitas diferentes que empregam carambolas, constando sete pratos principais, quatro biscoitos, 26 sobremesas e oito marmeladas, gelatinas ou similares (Saúco \& Menini, 1991). A planta se mantém sempre verde, com rápida entrada em produção e um número variável de florações ao longo do ano, encontrando-se concomitantemente folhas verdes, flores rosas ou roxas, frutos verdes e maduros (Saúco \& Menini, 1991). A maioria dos frutos é produzida nas partes expostas à insolação indireta. O fruto é uma baga carnosa, com forma ovóide ou elipsoidal, variando no tamanho entre 50-250 mm de comprimento e 30-100 mm de diâmetro, com peso comercial entre 100-250 g. Apresenta cinco costelas ou asas longitudinais, raramente 4-6, ainda que haja citação com duas e oito (Saúco \& Menini, 1991; citando Nand, 1967).

No sudeste asiático se tem realizado grande número de seleções de árvores procedentes de sementes, que se destacaram por alguma característica desejável sem que houvesse um plano adequado de melhoramento. A maior dificuldade de identificação desse material é a rápida entrada em produção e a ampla heterozigose (Miller \& MacDonald, 1990; Nagy et al., 1990; Saúco \& Menini, 1991).

Knight (1989) relacionou algumas características desejáveis de frutos, com peso adequado entre 100-300 $\mathrm{g}$; forma atrativa com cinco asas, cuja relação comprimento:asa seja 2:1; asas largas com ápice arredondado; cor atraente ideal, o amarelo intenso com cerosidade na epiderme; vida de prateleira longa; época de colheita adequada aos picos de preço, como as épocas de Natal e Páscoa na Europa; baixo número de sementes; epiderme tanto adequada ao consumo "in natura" como à proteção dos frutos; relação açúcar/acidez maior que $10^{\circ} \mathrm{Brix} / \mathrm{menor}$ que $5 \mathrm{meq} 100 \mathrm{~g}^{-1}$, com o teor

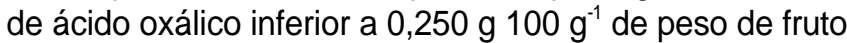
maduro; textura crocante; uso multivariado; resistência a moscas das frutas.
Neste trabalho caracterizaram-se caramboleiras oriundas de pomar comercial em relação às características biométricas e físico-químicas dos frutos, com potencialidade de utilização para consumo fresco e processamento agroindustrial.

\section{MATERIAL E MÉTODOS}

O experimento para seleção de caramboleiras, em relação às características biométricas e físico-químicas, dos tipos doces e ácidos de frutos, de interesse para 0 consumo fresco e processamento, respectivamente, foi avaliado na Universidade de São Paulo, na Escola Superior de Agricultura "Luiz de Queiroz", no Departamento de Produção Vegetal, no município de Piracicaba, SP.

Foram selecionadas para coleta de frutos, 15 caramboleiras (Averrhoa carambola L.) de pomar comercial, no município de Mirandópolis-SP. O solo da área experimental é areno-argiloso, com espaçamento de cultivo de 6,0 $\times 4,0 \mathrm{~m}$, com as entrelinhas mantidas com roçadeiras, sendo as plantas submetidas a podas de limpeza, raleio de frutos e controle fitossanitário preventivo.

Realizaram-se seis coletas (dezembro/1996, fevereiro e agosto/1997, maio/1998, fevereiro e julho/ 1999), constando 50 frutos por planta, para as avaliações biométricas de comprimento, diâmetro, massa, número de gomos e de sementes. Para a análise dos parâmetros físico-químicos: sólidos solúveis totais (SST), acidez total titulável (ATT), "ratio' (SST/ATT), pH, firmeza de polpa e cor de epiderme, foram realizadas nos referidos períodos, amostragens aleatórias, constando três frutos por planta, para avaliação no Centro de Energia Nuclear de Agricultura-Laboratório de Entomologia, em Piracicaba-SP.

Para mensuração do comprimento e diâmetro, em relação aos maiores eixos longitudinal e transversal dos frutos, respectivamente, utilizou-se paquímetro digital (DIGIMESS - $150 \mathrm{~mm}$ ); para a massa, foi usada a balança analítica de precisão (METLER). Quanto às avaliações físico-químicas, foram utilizadas as metodologias, listadas a seguir:

coloração externa: determinada com auxílio do colorímetro Minolta, Modelo CR-300, com sistema colorimétrico $\mathrm{L} \mathrm{C} \mathrm{h}$; realizando-se duas leituras por fruto na região medial dos gomos, sendo os resultados expressos em ângulo de cor $\left(\mathrm{h}^{\circ}\right)$, acordo com McGuirre (1992);

firmeza de polpa: determinada com auxílio do penetrômetro manual Effegi, modelo FT-327 e ponteira 5/ 16 ", realizando-se duas leituras por fruto na região medial dos gomos, sendo os resultados expressos em $\mathrm{Kg}$;

teor de sólidos solúveis totais (SST):obtido através de leitura direta em refratômetro marca SchimdtHaensch modelo SR-400, sendo os resultados expressos em ${ }^{0}$ Brix;

acidez total titulável (ATT): determinada através da metodologia descrita por Carvalho et al. (1990) e os resultados expressos em percentual de ácido oxálico; 
pH: obtido através de peagâmetro Digimed modelo DMPH-2, segundo metodologia indicada pelo Instituto Adolfo Lutz (1985).

Procedeu-se análise descritiva dos dados amostrais, para cada variável estudada em cada planta avaliada, sendo àqueles submetidos à análise estatística conforme suas características inerentes, utilizando-se a média aritmética, o desvio padrão amostral e o intervalo de confiança para a média. A análise estatística dos dados amostrais foi complementada com análise de agrupamento, que é uma técnica com uma variedade de algoritmos para agrupar indivíduos ou objetos dentro de grupos desconhecidos, porém similares; e "sun ray plot", que consiste em aplicar um fator de ponderação às médias de cada uma das variáveis estudadas (para transformálas em uma medida comparável em grandeza) em cada uma das plantas e plotar em cada eixo as distâncias (médias ponderadas) referentes a cada variável considerada.

\section{RESULTADOS E DISCUSSÃO}

Na TABELA 1 constam as freqüências observadas para o número de gomos durante os seis períodos de colheita.

Pelo teste de $\chi^{2}$ rejeita-se a hipótese de independência ao nível de $1 \%$ de significância, isto é, o número de gomos das carambolas é dependente das plantas, sendo comparada às plantas duas a duas, com os valores de $\chi^{2}$ apresentados na coluna "Comparação" da referida TABELA.

A planta $\mathrm{C} 1$ apresentou frutos com 5 gomos $(54,00 \%)$ e com 6 e 7 gomos $(46,00 \%)$, sendo significativamente diferente das outras plantas avaliadas. A planta C3 ocupou posição intermediária, com $74,00 \%$ de frutos com 5 gomos e $26,00 \%$ de frutos com 6 ou 7 gomos, diferindo significativamente de todas as plantas estudadas. A planta C2A apresentou a maior porcentagem de frutos com 5 gomos $(94,67 \%)$.

Na TABELA 2 são apresentados os resultados obtidos para o comprimento e diâmetro do fruto. Com relação ao comprimento, a planta $\mathrm{C} 1$ obteve a maior média $(116,61 \mathrm{~mm}$, com IC de 115,02 a 118,21 mm), sendo superior a todas as plantas analisadas; seguida pela planta $\mathrm{C} 3$, que somente não diferiu da planta $\mathrm{C} 2 \mathrm{C}$. A menor média foi obtida pela planta C3D $(86,43 \mathrm{~mm}$, com IC de 85,25 a $87,60 \mathrm{~mm}$ ), diferindo das demais plantas avaliadas.

Em relação ao diâmetro, a planta $\mathrm{C} 1$ obteve a maior média $(65,22 \mathrm{~mm}$; com IC de 64,31 a $66,13 \mathrm{~mm})$, diferindo das demais plantas estudadas; seguida da C3, que não diferiu somente das plantas C1C, C2, C2C e C2D. A menor média foi obtida na planta C3D $(47,30 \mathrm{~mm}$; com IC de 46,52 a 48,07 mm), diferindo estatisticamente de todas as outras plantas analisadas.

Na TABELA 3 são apresentados os resultados obtidos para a massa de carambolas. A planta $\mathrm{C} 1$ obteve a maior média (127,13 g, com IC de 122,42 a 131,84 g), diferindo de todas as outras plantas, seguida da planta $\mathrm{C} 2 \mathrm{C}$, que não diferiu somente das plantas $\mathrm{C} 2 \mathrm{D}$ e $\mathrm{C} 3$. A menor média foi obtida pela planta C3D $(64,88 \mathrm{~g}$; com IC de 63,29 a $66,47 \mathrm{~g}$ ), somente não diferindo da planta C2A.

$\mathrm{Na}$ TABELA 4 são apresentados os resultados obtidos para o número de sementes de carambolas. A

TABELA 1 - Freqüências observadas e referentes percentuais para número de gomos de carambolas. Piracicaba-SP, 1999.

\begin{tabular}{|c|c|c|c|c|c|c|c|c|}
\hline \multirow{2}{*}{$\frac{\text { Plantas }}{\text { C1 }}$} & \multicolumn{2}{|c|}{------------ 5 ------------ } & \multicolumn{2}{|c|}{ 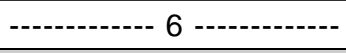 } & \multicolumn{2}{|c|}{------------ 7 ------------ } & \multirow{2}{*}{$\begin{array}{c}\text { Total } \\
300\end{array}$} & \multirow{2}{*}{$\frac{\text { Comparação }}{a}$} \\
\hline & 162 & $(54,00 \%)$ & 117 & $(39,00 \%)$ & 21 & $(7,00 \%)$ & & \\
\hline C1A & 268 & $(89,33 \%)$ & 30 & $(10,00 \%)$ & 2 & $(0,67 \%)$ & 300 & $\mathrm{~cd}$ \\
\hline C1B & 279 & $(93,00 \%)$ & 20 & $(6,67 \%)$ & 1 & $(0,33 \%)$ & 300 & $\mathrm{~cd}$ \\
\hline C1C & 274 & $(91,33 \%)$ & 26 & $(8,67 \%)$ & 0 & $(0,00 \%)$ & 300 & $\mathrm{~cd}$ \\
\hline C1D & 278 & $(92,67 \%)$ & 21 & $(7,00 \%)$ & 1 & $(0,33 \%)$ & 300 & $\mathrm{~cd}$ \\
\hline C2 & 265 & $(88,33 \%)$ & 31 & $(10,33 \%)$ & 4 & $(1,33 \%)$ & 300 & c \\
\hline $\mathrm{C} 2 \mathrm{~A}$ & 284 & (94,67\%) & 15 & $(5,00 \%)$ & 1 & $(0,33 \%)$ & 300 & d \\
\hline C2B & 278 & $(92,67 \%)$ & 22 & $(7,33 \%)$ & 0 & $(0,00 \%)$ & 300 & $\mathrm{~cd}$ \\
\hline $\mathrm{C} 2 \mathrm{C}$ & 264 & $(88,00 \%)$ & 36 & $(12,00 \%)$ & 0 & $(0,00 \%)$ & 300 & $c$ \\
\hline C2D & 266 & $(88,67 \%)$ & 33 & $(11,00 \%)$ & 1 & $(0,33 \%)$ & 300 & c \\
\hline C3 & 222 & $(74,00 \%)$ & 69 & $(23,00 \%)$ & 9 & $(3,00 \%)$ & 300 & b \\
\hline C3A & 268 & $(89,33 \%)$ & 32 & $(10,67 \%)$ & 0 & $(0,00 \%)$ & 300 & c \\
\hline C3B & 265 & $(88,33 \%)$ & 31 & $(10,33 \%)$ & 4 & $(1,33 \%)$ & 300 & c \\
\hline C3C & 277 & $(92,33 \%)$ & 23 & $(7,67 \%)$ & 0 & $(0,00 \%)$ & 300 & $\mathrm{~cd}$ \\
\hline C3D & 272 & $(90,67 \%)$ & 27 & $(9,00 \%)$ & 1 & $(0,33 \%)$ & 300 & $\mathrm{~cd}$ \\
\hline Total & 3922 & $(87,16 \%)$ & 533 & $(11,84 \%)$ & 45 & $(1,00 \%)$ & 4500 & \\
\hline
\end{tabular}

Plantas seguidas por letras diferentes diferem pelo teste de $\chi^{2}$ com $\alpha \leq 0,05$. 
planta C1C obteve a maior média (12,89, com IC de 12,24 a 13,54), não diferindo estatisticamente das plantas $C 1$, C1A, C1B e C1D. A menor média foi obtida pela planta C3 (5,83, com IC de 5,42 a 6,23), diferindo das demais plantas avaliadas.

$\mathrm{Na}$ TABELA 5 constam os resultados obtidos para a relação comprimento/diâmetro de carambolas. A planta C3C obteve a maior média $(1,86$, com IC de 1,84 a 1,88), não diferindo somente das plantas C1B, C2A, C3, C3B e C3D, que diferiram das demais plantas estudadas. A menor média foi obtida pela planta C1C $(1,75$, com IC de
1,73 a 1,77), que não diferiu somente das plantas $C 1 A$, C1D, C2B e C2D, que diferiram das demais.

Provavelmente, existe uma interação entre plantas e épocas de colheita, pois algumas plantas passam da maior média em uma época para a menor média na época posterior e vice-versa.

Nas TABELAS 6 e 7 constam os resultados obtidos para as variáveis sólidos solúveis totais (SST), pH, acidez total titulável (ATT), "ratio" (SST/ATT), firmeza de polpa e coloração de epiderme $\left(L, C\right.$ e $\left.h^{\circ}\right)$, nos frutos de 15 caramboleiras avaliadas.

TABELA 2 - Média, desvio padrão e intervalo de confiança para o comprimento e diâmetro de carambolas. Piracicaba-SP, 1999.

\begin{tabular}{lcccccc}
\hline Plantas & Comprimento(C) & Diâmetro(D) & \multicolumn{2}{c}{$\left(^{*}\right.$ Intervalo de Confiança (95\%) } & \multicolumn{2}{c}{ Desvio Padrão } \\
\hline C1 & \multicolumn{2}{c}{ Média $(\mathrm{mm})$} & $(\mathrm{C})$ & $(\mathrm{D})$ & $(\mathrm{C})$ & $(\mathrm{D})$ \\
\hline C1A & 116,61 & 65,22 & $115,02-118,21$ & $64,31-66,13$ & 14,05 & 8,00 \\
C1B & 92,18 & 52,75 & $91,35-93,01$ & $52,13-53,37$ & 7,30 & 5,45 \\
C1C & 94,17 & 51,55 & $93,23-95,11$ & $50,96-52,15$ & 8,27 & 5,22 \\
C1D & 99,66 & 57,31 & $98,28-101,04$ & $56,43-58,19$ & 12,14 & 7,71 \\
C2 & 97,96 & 55,17 & $96,79-99,13$ & $54,42-55,92$ & 10,28 & 6,60 \\
C2A & 102,39 & 57,40 & $101,37-103,41$ & $56,60-58,19$ & 8,95 & 7,00 \\
C2B & 93,08 & 51,40 & $92,11-94,04$ & $50,83-51,98$ & 8,48 & 5,07 \\
C2C & 93,76 & 52,92 & $92,91-94,60$ & $52,42-53,41$ & 7,46 & 4,33 \\
C2D & 103,94 & 57,66 & $102,78-105,10$ & $56,88-58,45$ & 10,22 & 6,91 \\
C3 & 100,05 & 57,18 & $98,85-101,25$ & $56,3-58,04$ & 10,57 & 7,55 \\
C3A & 104,81 & 58,10 & $103,58-106,04$ & $57,13-59,07$ & 10,83 & 8,57 \\
C3B & 90,53 & 50,08 & $89,38-91,68$ & $49,30-50,85$ & 10,12 & 6,83 \\
C3C & 94,40 & 51,78 & $93,12-95,68$ & $50,91-52,64$ & 11,25 & 7,63 \\
C3D & 94,03 & 50,79 & $92,71-95,34$ & $50,02-51,56$ & 11,55 & 6,79 \\
\hline
\end{tabular}

${ }^{*}$ Limite inferior e superior de confiança $(\mathrm{mm})$

TABELA 3 - Média, desvio padrão e intervalo de confiança (95\%) para a massa (g) de carambolas, Piracicaba-SP, 1999.

\begin{tabular}{lccc}
\hline Plantas & $\begin{array}{c}\text { Massa } \\
\text { média }\end{array}$ & $\begin{array}{c}\left(^{*} \text { Intervalo de }\right. \\
\text { Confiança }\end{array}$ & $\begin{array}{c}\text { Desvio } \\
\text { Padrão }\end{array}$ \\
\hline C1 & 127,13 & $122,42-131,84$ & 41,42 \\
C1A & 69,84 & $67,95-71,72$ & 16,55 \\
C1B & 72,03 & $70,31-73,75$ & 15,15 \\
C1C & 85,12 & $82,24-88,00$ & 25,34 \\
C1D & 79,91 & $77,28-82,54$ & 23,12 \\
C2 & 84,93 & $82,69-87,17$ & 19,74 \\
C2A & 67,01 & $65,51-68,50$ & 13,13 \\
C2B & 70,49 & $69,03-71,95$ & 12,88 \\
C2C & 91,12 & $88,19-94,06$ & 25,83 \\
C2D & 88,77 & $86,25-91,29$ & 22,17 \\
C3 & 90,45 & $86,39-94,52$ & 35,78 \\
C3A & 69,29 & $67,20-71,37$ & 18,32 \\
C3B & 73,59 & $71,19-75,98$ & 21,07 \\
C3C & 77,45 & $74,80-80,10$ & 23,30 \\
C3D & 64,88 & $63,29-66,47$ & 14,00 \\
\hline
\end{tabular}

${ }^{(*)}$ Limite inferior e superior de confiança $(\mathrm{mm})$
TABELA 4 - Média, desvio padrão e intervalo de confiança (95\%) para número de sementes de carambolas. Piracicaba,-SP, 1999.

\begin{tabular}{lccc}
\hline Plantas & $\begin{array}{c}\text { Média (no) } \\
\text { de sementes }\end{array}$ & $\begin{array}{c}\left(^{*}\right) \\
\text { Intervalo de } \\
\text { Confiança }\end{array}$ & $\begin{array}{c}\text { Desvio } \\
\text { Padrão }\end{array}$ \\
\hline C1 & 12,73 & $12,10-13,37$ & 5,61 \\
C1A & 12,27 & $11,79-12,76$ & 4,25 \\
C1B & 12,09 & $11,48-12,70$ & 5,38 \\
C1C & 12,89 & $12,24-13,54$ & 5,68 \\
C1D & 11,96 & $11,43-12,50$ & 4,73 \\
C2 & 10,95 & $10,42-11,48$ & 4,67 \\
C2A & 10,16 & $9,67-10,65$ & 4,27 \\
C2B & 10,24 & $9,82-10,67$ & 3,74 \\
C2C & 6,62 & $6,24-7,01$ & 3,37 \\
C2D & 8,21 & $7,75-8,68$ & 4,09 \\
C3 & 5,83 & $5,42-6,23$ & 3,54 \\
C3A & 8,85 & $8,47-9,22$ & 3,33 \\
C3B & 9,56 & $9,15-9,98$ & 3,67 \\
C3C & 9,56 & $9,07-10,04$ & 4,28 \\
C3D & 8,49 & $8,10-8,88$ & 3,44 \\
\hline
\end{tabular}

${ }^{(*)}$ Limite inferior e superior de confiança $(\mathrm{mm})$ 
TABELA 5 - Média, desvio padrão e intervalo de confiança (95\%) para a relação comprimento/diâmetro de carambolas. Piracicaba-SP, 1999.

\begin{tabular}{cccc}
\hline Plantas & $\begin{array}{c}\text { Comprimento/ } \\
\text { diâmetro (média) }\end{array}$ & $\begin{array}{c}\left(^{*} \text { Intervalo de }\right. \\
\text { Confiança }\end{array}$ & $\begin{array}{c}\text { Desvio } \\
\text { Padrão }\end{array}$ \\
\hline C1 & 1,80 & $1,78-1,82$ & 0,17 \\
C1A & 1,76 & $1,74-1,78$ & 0,17 \\
C1B & 1,84 & $1,82-1,86$ & 0,19 \\
C1C & 1,75 & $1,73-1,77$ & 0,19 \\
C1D & 1,78 & $1,77-1,80$ & 0,15 \\
C2 & 1,80 & $1,78-1,83$ & 0,21 \\
C2A & 1,82 & $1,80-1,84$ & 0,16 \\
C2B & 1,78 & $1,76-1,80$ & 0,16 \\
C2C & 1,81 & $1,80-1,83$ & 0,17 \\
C2D & 1,77 & $1,74-1,79$ & 0,20 \\
C3 & 1,82 & $1,80-1,84$ & 0,18 \\
C3A & 1,82 & $1,80-1,83$ & 0,14 \\
C3B & 1,84 & $1,82-1,86$ & 0,18 \\
C3C & 1,86 & $1,84-1,88$ & 0,16 \\
C3D & 1,84 & $1,82-1,86$ & 0,18 \\
\hline
\end{tabular}

$\left.{ }^{*}\right)$ Limite inferior e superior de confiança $(\mathrm{mm})$.
Para SST planta C3 obteve a maior média $(6,57$ com IC de 6,28 a 6,86), não diferindo das plantas $\mathrm{C1}$, C1A, $\mathrm{C} 1 \mathrm{~B}, \mathrm{C} 2$ e C2D, que diferiram das demais plantas analisadas. A menor média foi observada na planta $\mathrm{C} 2 \mathrm{~B}$ (4,91, com IC de 4,16 a 5,66), que diferiu somente das plantas C2 e C3.

Quanto ao $\mathrm{pH}$, as plantas $\mathrm{C} 1$ e $\mathrm{C} 2$ (3,32; com IC de 3,22 a 3,42 e 3,32, com IC de 3,12 a 3,52, respectivamente) obtiveram as maiores médias, sendo consideradas estatisticamente iguais às plantas C1A, C2D e C3, que diferiram das demais plantas estudadas. A menor média $(1,57$; com IC de 1,38 a 1,76 ) na planta $C 3 C$, que diferiu das plantas $C 1, C 1 A$, C2, C2D e C3, não diferindo das demais plantas avaliadas.

Em relação a $A T T$, a planta C3B alcançou a maior média $(1,41$; com IC de 0,80 a 2,01), diferindo somente da planta $\mathrm{C} 1$, não diferindo das demais plantas avaliadas. A menor média foi obtida pela planta $\mathrm{C} 1(0,56$; com IC de $0,35$ a 0,77$)$, diferindo das plantas C1D, C2A, C2B, C3A,

TABELA 6 - Média, desvio padrão e intervalo de confiança (95\%) para sólidos solúveis totais (SST), pH, acidez total titulável (ATT) e "ratio" (SST/ATT) de carambolas. Piracicaba-SP, 1999.

\begin{tabular}{|c|c|c|c|c|c|c|c|c|}
\hline \multirow[b]{4}{*}{ Plantas } & \multicolumn{4}{|c|}{ SST } & \multicolumn{4}{|c|}{$\mathrm{pH}$} \\
\hline & \multirow{2}{*}{\multicolumn{3}{|c|}{$\begin{array}{c}\text { Intervalo de } \\
\text { Confiança }\end{array}$}} & \multirow[b]{3}{*}{ D. Padrão } & \multirow[b]{3}{*}{ Média } & \multirow{2}{*}{\multicolumn{2}{|c|}{$\begin{array}{l}\text { Intervalo de } \\
\text { Confiança }\end{array}$}} & \multirow[b]{3}{*}{ D. Padrão } \\
\hline & & & & & & & & \\
\hline & Média & $\mathrm{LIC}^{1}$ & $\mathrm{LSC}^{2}$ & & & LIC & LSC & \\
\hline C1 & 5,99 & 5,13 & 6,84 & 0,82 & 3,32 & 3,22 & 3,42 & 0,09 \\
\hline C1A & 5,98 & 4,98 & 6,98 & 0,96 & 3,03 & 2,30 & 3,75 & 0,69 \\
\hline C1B & 5,65 & 4,59 & 6,70 & 1,00 & 2,03 & 1,43 & 2,64 & 0,58 \\
\hline $\mathrm{C} 1 \mathrm{C}$ & 5,31 & 4,63 & 5,98 & 0,64 & 1,80 & 1,63 & 1,97 & 0,16 \\
\hline C1D & 4,97 & 4,18 & 5,76 & 0,75 & 1,67 & 1,57 & 1,77 & 0,09 \\
\hline $\mathrm{C} 2$ & 6,40 & 5,71 & 7,09 & 0,65 & 3,32 & 3,12 & 3,52 & 0,19 \\
\hline $\mathrm{C} 2 \mathrm{~A}$ & 5,09 & 4,35 & 5,83 & 0,70 & 1,74 & 1,59 & 1,89 & 0,14 \\
\hline $\mathrm{C} 2 \mathrm{~B}$ & 4,91 & 4,16 & 5,66 & 0,71 & 1,71 & 1,59 & 1,83 & 0,11 \\
\hline $\mathrm{C} 2 \mathrm{C}$ & 5,27 & 4,62 & 5,93 & 0,63 & 1,89 & 1,28 & 2,50 & 0,58 \\
\hline $\mathrm{C} 2 \mathrm{D}$ & 5,75 & 5,10 & 6,41 & 0,63 & 2,79 & 2,20 & 3,37 & 0,56 \\
\hline C3 & 6,57 & 6,28 & 6,86 & 0,28 & 3,23 & 2,93 & 3,52 & 0,28 \\
\hline C3A & 4,99 & 4,52 & 5,46 & 0,45 & 1,84 & 1,67 & 2,01 & 0,16 \\
\hline C3B & 5,01 & 4,65 & 5,38 & 0,35 & 1,70 & 1,61 & 1,78 & 0,08 \\
\hline C3C & 5,20 & 4,62 & 5,78 & 0,55 & 1,57 & 1,38 & 1,76 & 0,18 \\
\hline \multirow[t]{3}{*}{ C3D } & 5,19 & 4,75 & 5,62 & 0,41 & 1,79 & 1,69 & 1,90 & 0,10 \\
\hline & \multicolumn{4}{|c|}{ ATT } & \multicolumn{4}{|c|}{ Ratio } \\
\hline & \multicolumn{3}{|c|}{ Int. de Confiança } & & & \multicolumn{2}{|c|}{ Int. de Confiança } & \\
\hline Plantas & Média & LIC & LSC & D. Padrão & Média & LIC & LSC & D. Padrão \\
\hline C1 & 0,56 & 0,35 & 0,77 & 0,20 & 11,78 & 7,07 & 16,50 & 4,49 \\
\hline $\mathrm{C} 1 \mathrm{~A}$ & 0,80 & 0,40 & 1,21 & 0,39 & 9,53 & 3,81 & 15,25 & 5,45 \\
\hline $\mathrm{C} 1 \mathrm{~B}$ & 1,14 & 0,67 & 1,61 & 0,45 & 5,88 & 2,53 & 9,22 & 3,19 \\
\hline $\mathrm{C} 1 \mathrm{C}$ & 1,19 & 0,76 & 1,62 & 0,41 & 5,00 & 2,75 & 7,25 & 2,15 \\
\hline C1D & 1,28 & 0,80 & 1,76 & 0,46 & 4,32 & 2,37 & 6,28 & 1,87 \\
\hline $\mathrm{C} 2$ & 0,59 & 0,38 & 0,81 & 0,20 & 11,81 & 7,64 & 15,98 & 3,97 \\
\hline $\mathrm{C} 2 \mathrm{~A}$ & 1,22 & 0,81 & 1,62 & 0,39 & 4,51 & 3,00 & 6,02 & 1,44 \\
\hline $\mathrm{C} 2 \mathrm{~B}$ & 1,25 & 0,85 & 1,65 & 0,38 & 4,18 & 2,90 & 5,47 & 1,23 \\
\hline $\mathrm{C} 2 \mathrm{C}$ & 1,16 & 0,66 & 1,66 & 0,48 & 5,50 & 2,08 & 8,91 & 3,25 \\
\hline C2D & 0,68 & 0,40 & 0,95 & 0,26 & 9,84 & 5,18 & 14,49 & 4,44 \\
\hline C3 & 0,68 & 0,38 & 0,97 & 0,28 & 11,16 & 6,53 & 15,80 & 4,42 \\
\hline C3A & 1,25 & 0,79 & 1,71 & 0,44 & 4,39 & 2,77 & 6,01 & 1,54 \\
\hline $\mathrm{C} 3 \mathrm{~B}$ & 1,41 & 0,80 & 2,01 & 0,58 & 4,02 & 2,59 & 5,45 & 1,36 \\
\hline $\mathrm{C} 3 \mathrm{C}$ & 1,33 & 0,85 & 1,80 & 0,45 & 4,33 & 2,67 & 5,99 & 1,58 \\
\hline C3D & 1,30 & 0,87 & 1,73 & 0,41 & 4,30 & 2,99 & 5,61 & 1,25 \\
\hline
\end{tabular}

(1)limite inferior de confiança; (2)limite superior de confiança. 
TABELA 7 - Média, desvio padrão e intervalo de confiança (95\%), para firmeza de polpa e coloração externa (L, C e ho) de carambolas. Piracicaba-SP, 1999.

\begin{tabular}{|c|c|c|c|c|c|c|c|c|}
\hline \multirow[b]{3}{*}{ Plantas } & \multicolumn{4}{|c|}{ Firmeza de polpa } & \multicolumn{4}{|c|}{$\mathrm{L}$} \\
\hline & \multirow[b]{2}{*}{ Média } & \multicolumn{2}{|c|}{$\begin{array}{c}\text { Intervalo de } \\
\text { Confiança }\end{array}$} & \multirow[b]{2}{*}{ D. Padrão } & \multirow[b]{2}{*}{ Média } & \multicolumn{2}{|c|}{$\begin{array}{c}\text { Intervalo de } \\
\text { Confiança }\end{array}$} & \multirow[b]{2}{*}{ D. Padrão } \\
\hline & & $\mathrm{LIC}^{1}$ & $\mathrm{LSC}^{2}$ & & & LIC & LSC & \\
\hline $\mathrm{C} 1$ & 4,87 & 3,47 & 6,26 & 1,33 & 46,78 & 45,09 & 48,47 & 1,61 \\
\hline C1A & 5,81 & 4,52 & 7,11 & 1,23 & 47,89 & 45,82 & 49,97 & 1,98 \\
\hline C1B & 5,97 & 4,63 & 7,30 & 1,27 & 46,43 & 44,43 & 48,43 & 1,90 \\
\hline C1C & 5,78 & 4,35 & 7,22 & 1,37 & 48,69 & 45,49 & 51,89 & 3,05 \\
\hline C1D & 5,45 & 4,14 & 6,76 & 1,25 & 46,79 & 44,99 & 48,60 & 1,72 \\
\hline $\mathrm{C} 2$ & 5,44 & 4,35 & 6,54 & 1,04 & 49,46 & 46,35 & 52,58 & 2,97 \\
\hline $\mathrm{C} 2 \mathrm{~A}$ & 6,11 & 4,72 & 7,50 & 1,32 & 47,24 & 45,26 & 49,22 & 1,88 \\
\hline $\mathrm{C} 2 \mathrm{~B}$ & 6,94 & 5,79 & 8,08 & 1,09 & 48,67 & 44,87 & 52,47 & 3,62 \\
\hline $\mathrm{C} 2 \mathrm{C}$ & 6,01 & 5,00 & 7,02 & 0,96 & 47,55 & 44,09 & 51,01 & 3,30 \\
\hline C2D & 5,94 & 4,85 & 7,04 & 1,04 & 47,69 & 43,48 & 51,89 & 4,01 \\
\hline $\mathrm{C} 3$ & 5,81 & 4,93 & 6,69 & 0,84 & 46,47 & 43,77 & 49,17 & 2,57 \\
\hline C3A & 5,28 & 4,69 & 5,88 & 0,57 & 48,73 & 45,04 & 52,43 & 3,52 \\
\hline $\mathrm{C} 3 \mathrm{~B}$ & 5,49 & 4,99 & 6,00 & 0,48 & 50,88 & 47,63 & 54,13 & 3,10 \\
\hline $\mathrm{C} 3 \mathrm{C}$ & 5,87 & 4,56 & 7,18 & 1,25 & 49,06 & 45,55 & 52,57 & 3,34 \\
\hline \multirow[t]{3}{*}{ C3D } & \multirow{2}{*}{\multicolumn{4}{|c|}{$\mathrm{C}$}} & \multirow{2}{*}{\multicolumn{4}{|c|}{$\mathrm{h}^{\circ}$}} \\
\hline & & & & & & & & \\
\hline & \multicolumn{3}{|c|}{ Int. de Confiança } & & & \multicolumn{2}{|c|}{ Int. de Confiança } & \\
\hline Plantas & Média & LIC & LSC & D. Padrão & Média & LIC & LSC & D. Padrão \\
\hline $\mathrm{C} 1$ & 25,22 & 21,73 & 28,72 & 3,33 & 109,84 & 106,75 & 112,93 & 2,94 \\
\hline $\mathrm{C} 1 \mathrm{~A}$ & 25,99 & 24,00 & 27,97 & 1,89 & 109,48 & 104,94 & 114,02 & 4,33 \\
\hline C1B & 25,82 & 23,14 & 28,50 & 2,55 & 111,21 & 107,33 & 115,09 & 3,70 \\
\hline C1C & 22,81 & 18,21 & 27,41 & 4,38 & 108,68 & 102,47 & 114,89 & 5,92 \\
\hline C1D & 22,55 & 20,87 & 24,23 & 1,60 & 110,32 & 105,26 & 115,37 & 4,82 \\
\hline C2 & 25,26 & 21,81 & 28,70 & 3,28 & 107,82 & 102,26 & 113,38 & 5,30 \\
\hline $\mathrm{C} 2 \mathrm{~A}$ & 20,60 & 17,43 & 23,77 & 3,02 & 112,23 & 109,71 & 114,75 & 2,40 \\
\hline $\mathrm{C} 2 \mathrm{~B}$ & 23,00 & 19,57 & 26,42 & 3,26 & 113,03 & 110,83 & 115,24 & 2,10 \\
\hline $\mathrm{C} 2 \mathrm{C}$ & 23,63 & 21,45 & 25,82 & 2,09 & 110,41 & 106,35 & 114,47 & 3,87 \\
\hline C2D & 24,50 & 19,99 & 29,00 & 4,29 & 113,34 & 110,46 & 116,22 & 2,75 \\
\hline $\mathrm{C} 3$ & 25,29 & 23,40 & 27,18 & 1,80 & 107,12 & 103,32 & 110,92 & 3,62 \\
\hline C3A & 23,19 & 20,61 & 25,78 & 2,46 & 109,02 & 105,74 & 112,31 & 3,13 \\
\hline C3B & 28,89 & 26,65 & 31,13 & 2,13 & 107,63 & 104,13 & 111,13 & 3,34 \\
\hline C3C & 22,52 & 18,79 & 26,26 & 3,56 & 107,26 & 101,19 & 113,32 & 5,78 \\
\hline C3D & 21,94 & 19,33 & 24,55 & 2,49 & 109,98 & 107,11 & 112,84 & 2,73 \\
\hline
\end{tabular}

(1) Limite inferior de confiança; ${ }^{(2)}$ Limite superior de confiança.

C3B, C3C e C3D, que não diferiram das demais caramboleiras avaliadas.

Em relação ao "ratio" que a maior média foi obtida pela planta C2 $(11,81$; com IC de 7,64 a 15,98), embora não tenha sido superior às plantas $\mathrm{C} 1, \mathrm{C} 1 \mathrm{~A}, \mathrm{C} 1 \mathrm{~B}, \mathrm{C} 2 \mathrm{C}$, $\mathrm{C} 2 \mathrm{D}$ e $\mathrm{C} 3$, que diferiram das demais. A menor média foi observada na planta C3B (4,02; com IC de 2,59 a 5,45), diferindo somente das plantas C1, C2 e C3.

Quanto à firmeza de polpa, a planta C2B obteve a maior média $(6,94$; com IC de 5,79 a 8,08$)$ embora não tenha sido superior as demais. Detectou-se menor média $(4,87$; com IC de 3,47 a 6,26$)$ na planta C1.

Na variável coloração de epiderme, através do parâmetro $L$, que indica brilho, as plantas não foram estatisticamente diferentes. Como a escala varia a 0 a 100 , os frutos apresentam-se nem brilhantes, tampouco opacos.

Em relação ao parâmetro C ("Chroma"), que indica intensidade de cor, a planta C3B obteve a maior média (28,89; com IC de 26,65 a 31,13$)$, diferindo das plantas C1D, C2A, C2B, C2C, C3A, C3C e C3D, não diferindo das demais. A menor média foi obtida pela planta C2A $(20,60$, com IC de 17,43 a 23,77), diferindo somente das plantas $\mathrm{C} 1 \mathrm{~A}$ e $\mathrm{C} 3 \mathrm{~B}$.

Quanto ao $\mathrm{h}^{\circ}$ ("hue angle"), que indica matiz da cor, que os frutos não apresentaram diferenças entre si. $O$ valor médio obtido encontra-se próximo a 110, o que corresponde a uma cor amarela esverdeada.

$\mathrm{Na}$ Figura 1 consta o diagrama de dispersão das médias de comprimento versus diâmetro dos frutos de caramboleiras. A planta $\mathrm{C} 1$ está isolada das demais, apresentando a maior média em ambos as variáveis, o que já havia sido verificado pelos intervalos de confiança. Além disso, um grupamento com médias intermediárias, em ordem decrescente composto pelas plantas $\mathrm{C} 3, \mathrm{C} 2 \mathrm{C}, \mathrm{C} 2$, C2D, C1C e C1D. As demais plantas podem ser consideradas inferiores em relação a essas variáveis. Há uma relação linear entre essas variáveis (com coeficiente de correlação igual a 0,977 , significativo a 0,01 pelo teste "t"), considerando-se que a medida que aumenta o comprimento ocorre o mesmo em relação ao diâmetro e vice-versa. 
Na Figura 2 consta o diagrama de dispersão das médias de número de sementes versus sólidos solúveis totais (SST) de frutos de caramboleiras. Observa-se não ocorrer nenhuma tendência de correlação. Nota-se, porém, que a planta C3 encontra-se isolada no diagrama, com um SST elevado em relação às demais, e também com um pequeno número de sementes, característica interessante para frutos comercializados para consumo fresco.

O diagrama de dispersão das médias de sólidos solúveis totais (SST) versus acidez total titulável (ATT) é apresentado na Figura 3. Observa-se que 5 plantas apresentaram médias baixas de ATT e altas de SST em relação às demais, formando assim um grupo composto pelas plantas $\mathrm{C} 1, \mathrm{C} 1 \mathrm{~A}, \mathrm{C} 2, \mathrm{C} 2 \mathrm{D}$ e $\mathrm{C} 3$, enquanto outro grupo é formado pelas demais plantas, tendo características inversas ao primeiro grupo. Observou-se também uma relação linear negativa entre as duas variáveis.

$\mathrm{Na}$ figura 4 são apresentadas as referências para o modelo "sun ray plot", enquanto na figura 5 constam os diagramas de cada uma das plantas estudadas, considerando-se as variáveis: comprimento, massa, número de sementes, "ratio", SST e ATT de carambolas.

Campbell (1965); descrevendo o cultivar Golden Star, dimensionou seus frutos com cinco ou seis gomos,

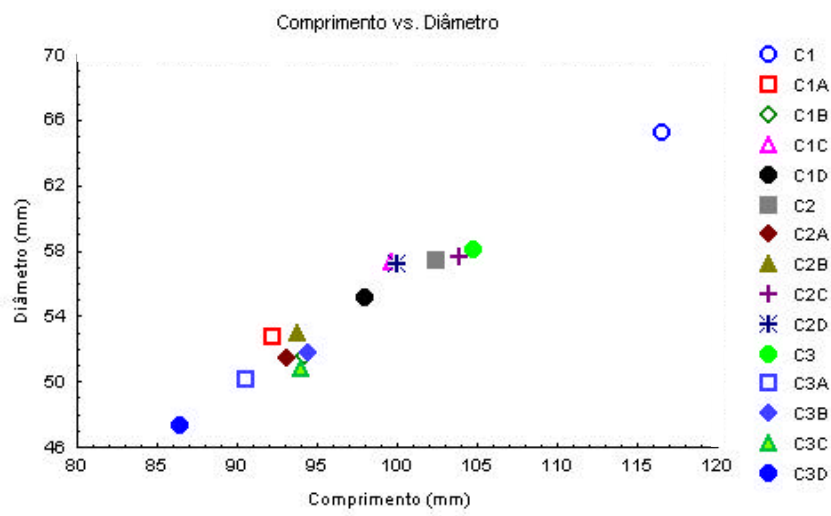

Figura 1 - Diagrama de dispersão das médias de comprimento versus diâmetro de carambolas. Piracicaba-SP, 1999.

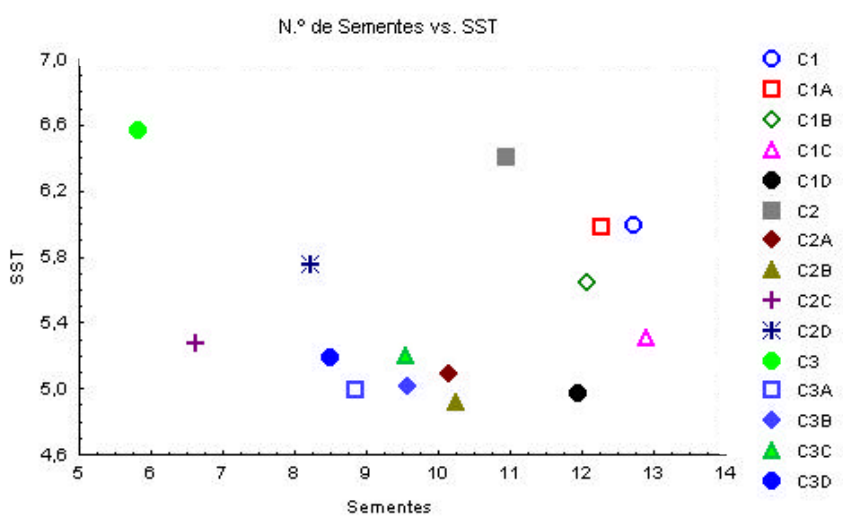

Figura 2 - Diagrama de dispersão das médias de número de sementes versus sólidos solúveis totais (SST) de carambolas. Piracicaba-SP, 1999.

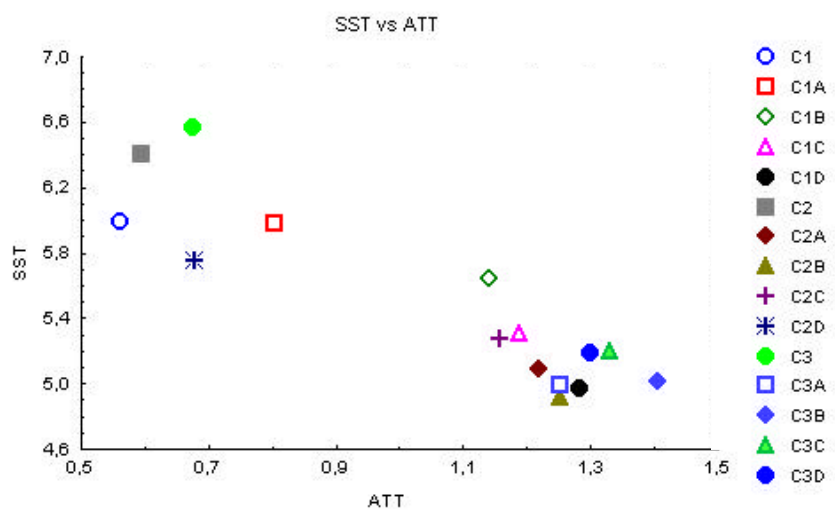

Figura 3 - Diagrama de dispersão das médias de sólidos solúveis totais (SST) versus acidez total titulável (ATT) de carambolas. Piracicaba-SP, 1999.

comprimento de 91,6-127,0 mm e massa entre 113,4-226,8 g. Wagner et al. (1975) reportaram sobre algumas cultivares de caramboleiras, selecionadas para produção comercial de frutos, que apresentaram valores médios de: comprimento $(6,1-10,0 \mathrm{~cm})$, massa $(54,0-111,0 \mathrm{~g})$, número de sementes (2-9), $\mathrm{pH}(2,3-4,9)$, sólidos solúveis totais (5,0-9,9 ${ }^{\circ}$ Brix), acidez (2,02-13,1 meq $\left.100 \mathrm{~g}^{-1}\right)$ e ácido oxálico $\left(0,039-0,679\right.$ meq $\left.100 \mathrm{~g}^{-1}\right)$.

Narain et al. (1988) avaliaram 143 frutos de caramboleiras comuns no trópico semi-árido na Paraíba, obtendo valores médios de comprimento $(6,80 \mathrm{~cm})$, diâmetro $(4,73 \mathrm{~cm})$, razão comprimento/diâmetro $(1,44)$, número de gomos (5) e número de sementes (4), que representaram em média $0,01 \%$ da massa $(46,14 \mathrm{~g})$ dos frutos.

Tidbury (1988) reportando sobre a seleção de caramboleiras em Palmira (Colômbia), comparou os frutos do cultivar Icambola com um tipo comum local, observando as seguintes variações quanto ao comprimento: $7,31 \mathrm{e}$ 7,64 cm; diâmetro: 4,09 e 4,14 cm; massa: 58,1 e 49,9 g; sólidos solúveis (SS): 8,9 e 7,9 \%; SS/ácidos: 1,85 e 3,99 e $\mathrm{pH}: 4,2$ e 4,0, respectivamente.

Oliveira et al. (1989a) determinaram as características físicas de 100 frutos de caramboleiras comuns no Ceará, encontrando valores médios para comprimento e diâmetro de 7,74 e 4,51 cm, respectivamente; massa de $56,75 \mathrm{~g}$ e refugo em escala piloto de 21,82\%. Oliveira et al. (1989b) utilizando $2,0 \mathrm{Kg}$ de frutos, caracterizaram os aspectos físico-químicos de carambolas do tipo comum, encontrando $\mathrm{pH}=3,33$, SST = $5,10^{\circ}$ Brix, ATT $=0,37 \%$ de ácido cítrico e "ratio" $=13,78$.

Andrews (1989) descreveu comparativamente algumas características de frutos de diferentes cultivares de caramboleiras em Trinidad, encontrando valores para massa entre 58,2-259,5 g; $\mathrm{pH}=1,25-3,51$ e SST $=4,9-11,8^{\circ}$ Brix. Neog \& Mohan (1991) encontraram aos 45 dias após o pegamento, valores médios de massa $(47,5 \mathrm{~g})$, comprimento $(7,59 \mathrm{~cm})$, diâmetro $(4,40 \mathrm{~cm})$, SST $\left(6,5^{\circ} \mathrm{Brix}\right), \mathrm{pH}(2,9)$, ATT $(0,61 \%$ de ácido anídrico) e "ratio" (SST/ATT, 10,8).

As médias e os intervalos médios de máxima e mínima para: comprimento $(C, \mathrm{~mm})$; diâmetro $(\mathrm{D}, \mathrm{mm})$; massa ( $\mathrm{M}, \mathrm{g})$; número de sementes (S); comprimento/ 


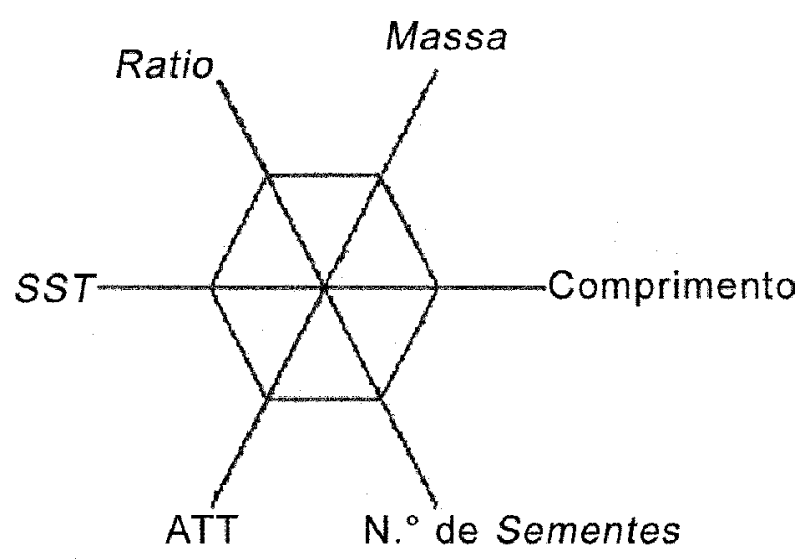

Figura 4 - Referência para o modelo "sun ray plot".

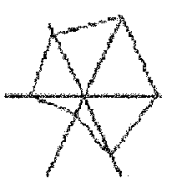

C1

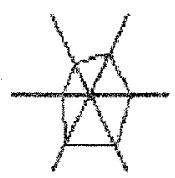

C1D

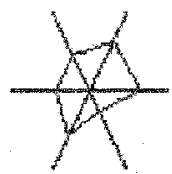

$\mathrm{C} 2 \mathrm{C}$

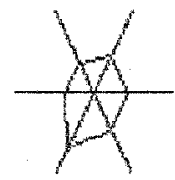

$\mathrm{C} 3 \mathrm{~B}$



C1A

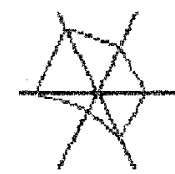

$\mathrm{C2}$
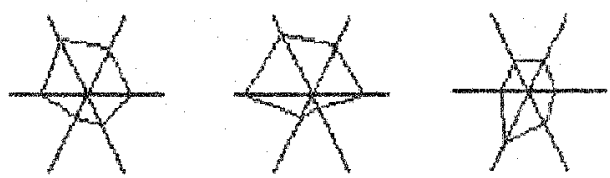

C3A
Figura 5 - "Sun ray plot" relacionando comprimento, massa, número de sementes, SST, acidez total titulável ATT e "ratio" de carambolas. Piracicaba-SP, 1999. diâmetro (C/D); sólidos solúveis totais (SST, ${ }^{\circ B}$ Brix); acidez total titulável (ATT, \% ácido oxálico); "ratio" (R, SST/ATT); firmeza de polpa (F); pH e o \% de frutos com cinco, seis e sete gomos $(G)$; obtidos neste trabalho, constam na TABELA 8.

As médias obtidas nas carambolas referentes às plantas C1 e C3, para comprimento (116,61 e 104,81 mm), diâmetro $(65,22$ e $58,10 \mathrm{~mm})$, relação comprimento/ diâmetro $(1,80$ e 1,82), massa $(127,13$ e 90,45 g), SST (5,99 e 6,57 'Brix), "ratio" (11,78 e 11,16), apresentaram um padrão superior em relação a: média geral das plantas avaliadas; média dos cultivares encontradas por Wagner et al. (1975); cultivar Icambola descrita por Tidbury (1988); valores encontrados por Neog \& Mohan (1991); média dos frutos comuns descritos na Paraíba e Ceará por Narain et al. (1988) e Oliveira et al. (1989a;1989b), respectivamente.

Os dados obtidos nessas plantas foram equivalentes aos cultivares: Arkin, com massa entre 90 e $200 \mathrm{~g}$; B-2, comprimento entre 80 e $120 \mathrm{~mm}$ e massa entre 100-200 g, embora o diâmetro tenha sido inferior ao encontrado (80 mm); Golden Star, com 100-150 mm de comprimento e massa entre 100-200 g. Contudo, apresentaram um padrão inferior em relação às cultivares: Cheng Tsei, que alcança massa de 315,0 g após o raleio; B-10, com $140 \mathrm{~mm}$ de comprimento, diâmetro entre 70-80 mm e massa de até $315 \mathrm{~g}$ após o raleio; B-17,com 15-18\% de SST, descritas por Saúco \& Menini (1991).

Com relação às características comerciais desejáveis para os frutos, recomendadas por Knight (1989), os resultados obtidos em relação às referidas plantas equivalem àqueles valores de massa entre 100$300 \mathrm{~g}$, com predominância $(87,16 \%)$ de cinco gomos e coloração amarela intensa com cerosidade na epiderme, quando maduros (não documentado). Embora, tenham sido obtidos valores inferiores na relação comprimento/ diâmetro (2:1) e sólidos solúveis totais (10 ํrix).

Com relação aos parâmetros químicos analisados nos frutos dessas caramboleiras, os resultados obtidos estiveram numa faixa média inferior daqueles valores médios de SST (5,0-9,9; 5,10; 4,9-11,8 e 6,5 ${ }^{\circ}$ Brix) encontrados por Wagner et al. (1975); Oliveira et al. (1989a); Andrews (1989) e Neog \& Mohan (1991), respectivamente. $\mathrm{O}$ "ratio" obtido foi equivalente àquele

TABELA 8 - Médias e intervalos de máxima e mínima dos parâmetros biométricos e físico-químico de carambolas. Piracicaba - SP, 1999.

\begin{tabular}{|c|c|c|c|c|c|c|c|c|c|c|c|}
\hline Variáveis & C & D & $M$ & $S$ & $\mathrm{C} / \mathrm{D}$ & SST & ATT & $\mathrm{R}$ & $\mathrm{F}$ & $\mathrm{pH}$ & $\mathrm{G}$ \\
\hline & $\mathrm{m}$ & & g & & & ${ }^{\circ}$ Brix & $\%$ & & & & $\%$ \\
\hline Média & 97,6 & 54,44 & 80,80 & 10 & 1,81 & 5,49 & 1,06 & 6,37 & 5,78 & 2,23 & $11,84(6)$ \\
\hline Máxima & 116,61 & 65,22 & 127,13 & 13 & 1,86 & 6,57 & 1,41 & 11,81 & 6,94 & 3,32 & $87,16(5)$ \\
\hline Mínima & 86,43 & 47,30 & 64,88 & 6 & 1,75 & 4,91 & 0,56 & 4,02 & 4,87 & 1,57 & $1,00(7)$ \\
\hline
\end{tabular}


encontrado $(13,78)$ por Oliveira et al. $(1989 a)$ e $(10,8)$ por Neog \& Mohan (1991).

Quanto à acidez total titulável essas plantas apresentaram baixos teores de ácido oxálico $(\mathrm{C} 1=0,56$ $\%$ e C2 $=0,68 \%$ ) em relação ao percentual médio geral encontrado (1,06\%), nas carambolas colhidas no estádio 'de vez', ratificado pelos resultados médios obtidos para $h^{\circ}=110$, o que corresponde na escala de matiz à cor amarela esverdeada, ponto de colheita visual adotado pelo produtor .

Algumas plantas apresentaram percentuais altos de ATT e baixos teores de SST, formando assim um grupo composto pelas plantas C3B, C1D, C2C, C3C e C3D, destacando-se a planta $\mathrm{C} 2 \mathrm{C}$ pelo baixo número de sementes, sendo inviáveis ao consumo fresco, contudo interessante ao processamento agroindustrial.

Dentre os resultados médios obtidos, aquele que apresentou maior desvantagem em relação aos padrões e tendência de consumo tanto fresco como processado e literatura consultada, foi a quantidade média de sementes, destacando-se a planta C1 (12,73), tanto em relação à planta C3 $(5,83)$ quanto àqueles valores médios encontrados (2-9 e 4) por Wagner et al. (1975) e Narain et al. (1988), respectivamente.

Do ponto de vista de tendência de mercado, do menor volume para conservação em frio, maior volume transportado e melhor acondicionamento, além de proporcionar consumo em único momento, não retornando a frigoconservação, são atribuídas como vantagens àqueles com dimensões menores daquelas encontradas na literatura internacional.

\section{REFERÊNCIAS BIBLIOGRÁFICAS}

ANDREWS, L. Prospects for carambola production in Trinidad and Tobago. Proceedings of Interamerican Society of the Tropical Horticulture, v.33, p.44-46, 1989.

ARAÚJO, P.S.R. de; SCARPARE FILHO, J.A.; MINANI, K. Carambola: fruto com formato e sabor únicos. Piracicaba: ESALQ, DIBD, 2000. 34p. (Série Produtor Rural, 12)

CAMPBELL, C.W. The golden star carambola. Gainesville: University of Florida, Florida Experiment Station, 1965. 6p. (Circular, S-173).

CARVALHO, C.R.L.; MANTOVANI, D.M.B.; CARVALHO, P.R.N.; MORAES, R.M.M. Análise química dos alimentos. Campinas: ITAL, 1990. 121p. (Manual Técnico).

DONADIO, L.C. Carambola growing in Brazil. Proceedings of the Interamerican Society of the Tropical Horticulture, v.33, p.26-29, 1989.
FERREIRA, F.R.; DONADIO, L.C. Banco ativo de germoplasma de fruteiras tropicais e subtropicais da UNESP/FCAVJ. In: CONGRESSO BRASILEIRO DE FRUTICULTURA, 9., Fortaleza, 1988. Anais. Fortaleza: SBF, 1988. p.770-771.

FERREIRA, F.R.; FERREIRA, S.A.N.; CARVALHO, J.E.V. Espécies frutíferas pouco exploradas com potencial econômico e social para o Brasil. Revista Brasileira de Fruticultura, v.9, p.11-22, 1987.

GRANATO, L. Cultura da caramboleira. São Paulo: Pocai \& Companhia, 1919. 10p. (Biblioteca Agrícola Granato).

INSTITUTO ADOLFO LUTZ. Normas analíticas: métodos químicos e físicos para análises de alimentos. 3.ed. São Paulo, 1985. 533p.

KNIGHT, R.J. Carambola cultivars and improvement programmes Proceedings of the Interamerican Society of the Tropical Horticulture, v.33, p.72-78, 1989.

McGUIRRE, R.G. Reporting of objective color measurements. Hortscience, v.27, p.1254-1255, 1992.

MILLER, W.R.; McDONALD, R.E. Condition of Florida carambolas after hot-air treatment and storage. Proceedings of the Florida State for Horticultural Society, v.103, p.238-241, 1990.

NAGY, S.; BARROS, S.; CARTER, R. Production and characterization of carambola essence. Proceedings of the Florida State for Horticultural Society, v.103, p.277-279, 1990.

NARAIN, N.; BORA, P.S.; HOLSCHUH, H.J.; VASCONCELOS, M.A.S.; SANTOS, C.M.G. dos. Caracterização física dos frutos de caramboleira oriundos do trópico semi-árido da Paraíba. In: CONGRESSO BRASILEIRO DE FRUTICULTURA, 9., Fortaleza, 1988. Anais. Fortaleza: SBF, 1988. p.205-208.

NEOG, M.; MOHAN, N.K. Growth and development of carambola (Averrhoa carambola L.) South Indian Horticulture, v.39, p.174-178, 1991.

OLIVEIRA, M.N.; MAIA, G.A.; GUEDES, Z.B.L.; GUIMARÃES, A.C.L.; FIGUEIREDO, R.W. de. Estudo das características físicas e do rendimento da carambola (Averrhoa carambola L.). Ciência Agronômica, v.20, p.97-99, 1989a.

OLIVEIRA, M.N.; MAIA, G.A.; GUEDES, Z.B.L.; GUIMARÃES, A.C.L.; FIGUEIREDO, R.W. de. Características químicas $e$ físico-químicas da carambola (Averrhoa carambola L.). Ciência Agronômica, v.20, p.129-133, 1989b.

SAÚCO, V.G. Possibilities of non-citrus tropical fruit in the Mediterranean. Acta Horticulturae, n.365, p.25-41, 1994.

SAÚCO, V.G.; MENINI, U.G. La carambola y su cultivo. Roma: FAO, 1991. 96p. (Estudios FAO. Producción y Protección Vegetal, 108).

TIDBURY, G.E. Averrhoa spp.: carambola and bilimbi. In: GARDNER, R.J.; CHAUDRI, A. The propagation of tropical fruit trees. Rome: FAO, 1988. p.291-303.

WAGNER, C.H.J.; BRYAN, W.L.; BERRY, R.E.; KNIGHT, R.J. Carambola selection for commercial production. Proceedings of the Florida State Horticultural Society, v.88, p.466-469, 1975.

Recebido em 31.01 .00 